ming // Asia Pac J Clin Nutr. - 2003. - Vol. 12. - Suppl. S5.

21. Ottonello S. Oxidative stress and age-related cataract / S. Ottonello, C. Foroni, A. Carta // Ophthalmologica. 2000. - Vol. 214 (1). - P. 78-85.

22. Schichi H. Cataract formation and prevention / H. Schichi // Expert Opion Invest Drugs. - 2004. - Vol. 13 (6). P. 691-701.

23. Spector A. Oxidative stress-induced cataract: mechanism of action / A. Spector // FASEB J. - 1995. - V. 9. P. $1173-1182$.
24. Taylor A. Nutritional influences on risk for cataract / A. Taylor // Int. Ophthalmol. Clin. - 2000. - Vol. 40 (4). - P. 17-49.

25. Truscott R. J. Age-related nuclear cataract-oxidation is the key / R. J. Truscott // Exp Eye Res. - 2005. - Vol. 80 (5). - P. 709-725.

26. Yablonski M. E. The presence of cataract as a predictor of mortality / M. E. Yablonski // Arch Ophthalmol. 2001. - Vol. 119 (10). - P. 1562-1563.

Поступила 30.03.2011

\title{
CORRECTION EFFECT OF EMOXIPINE ON THE PEROXIDATION PROCESSES IN THE LENS, HU- MOR AND TEAR FLUID IN EXPERIMENTAL KERATITIS AND EXPOSURE TO LIGHT
}

\section{Ya. Usov, Tarik Abod Tarboush, E. I. Kondratjeva}

Odessa, Ukraine

The experiment on 54 rabbits was made to study the influence of experimental keratitis and exposure to light on the condition of the antioxidant system of the lens, humor and tear fluid as well as possibility its disturbance correction with the help of emoxipine.

There was established reduction of the level of glutathione-peroxidase and catalase in keratitis by $25 \%$ and $22.1 \%$ respectively; in exposure to light it was by $33.8 \%$ and $28.7 \%$ respectively in comparison with the norm.

There was also seen the increase of the level of peroxide oxidation of lipid products in the lens especially marked in exposure to light.

While using emoxipine there was noted increased potential of the antioxidant system and decreased level of peroxide oxidation of lipid products in the lens in modeling cataract against the background of keratitis.

УДК 617.7-002-02:576.8-085-092.9

\section{ФОТОДИНАМИЧЕСКАЯ ТЕРАПИЯ С 0,1 \% МЕТИЛЕНОВЫМ СИНИМ В КОМБИНАЦИИ С 10 \% ДИМЕТИЛСУЛЬФОКСИДОМ В ЛЕЧЕНИИ ЭНДОФТАЛЬМИТОВ БАКТЕРИАЛЬНОЙ ЭТИОЛОГИИ}

\author{
А. В. Зборовская, канд. мед. наук \\ ГУ «Институт глазных болезней и тканевой терапии им. В. П. Филатова НАМН Украины» \\ Одесса, Украина
}

\begin{abstract}
Експеримент проведено на 20 очах кроликів породи шиншила. Модель ендофтальміту була виконана шляхом введення в склисте тіло 300 тисяч мікробних тіл (MT) в 0,1 мл добової культури патогенних тест-штамів Escherichia coli (150 тисяи MT) (ATCC O55K5) ma Staphylococcus aureus (150 тис MT) (АТCC 25923F-49). Лікування розпочиналось на другу добу (розвиток ендофтальміту): в контрольній групі (10 очей) -стандартна протизапальна терапія, в основній групі (10 очей) - до стандартної терапії долучали фотодинамічну терапію з метиленовим синім (активуючий діодний лазер 630 нм, тривалість опромінення 3 хв). В результаті встановлено, що застосування ФДТ з метиленовим синім дозволяє скоротити термін лікування ендофтальміту та досягти припинення запалення і санації тканин ока.
\end{abstract}

Ключевые слова: эндофтальмит, фотодинамическая терапия, метиленовый синий, эксперимент

Ключові слова: ендофтальміт, фотодинамічна терапія, метиленовий синій, експеримент

Введение. Бактериальные эндофтальмиты воспаления в результате попадания инфекционного агента в полость стекловидного тела при глазной хирургии и проникающих травмах глаз [5]. Среди всех случаев бактериального эндофтальмита послеоперационный эндофтальмит составляет 56-63\%, травматический - 22-44 \% и лишь единичные случаи связаны с прогрессированием и внедрением в полость глаза инфекции роговицы и склеры. Практически любая операция, сопровождающаяся вскрытием полости глаза, может привести к развитию внутриглазной инфекции. Описаны случаи

(C) А. В. Зборовская, 2011 
эндофтальмита после экстракции катаракты, витрэктомии, антиглаукоматозной операции, сквозной кератопластики [9], задней капсулотомии, репозиции ИОЛ [4], парацентеза передней камеры [6], случайных перфораций при кератотомии [3] и устранении косоглазия [8].

Лечение бактериальных эндофтальмитов остается одной из наиболее сложных проблем в офтальмологии, несмотря на наличие широкого спектра антибиотиков и витреоретинальной хирургии. Антибактериальное лечение успешно проводится с помощью интравитреального введения антибиотиков, однако прогноз по зрению обычно плохой, что связано с поражением нейросенсорной части сетчатки и пигментного эпителия сетчатки.

Альтернативным методом лечения локальных инфекционных процессов является фотодеструкция инфекционных агентов. Фотодеструкция инфекционных агентов (фотодинамическая антимикробная химиотерапия) - это уничтожение микроорганизмов с помощью фотосенсибилизаторов при облучении светом определённой длины волны $[7,10]$.

Диметилсульфоксид (ДМСО) впервые был получен в 1866 году, но лишь в начале 60-х годов ХХ ст. появились сообщения об использовании ДМСО в фармакологии и медицине. Было установлено, что ДМСО обладает противовоспалительным и антимикробным действием за счет высокой проницаемости через биологические мембраны [2].

Целью исследования было изучить в эксперименте на модели бактериального эндофтальмита эффективность фотодинамической терапии с $0,1 \%$ метиленовым синим в комбинации с $10 \%$ диметилсульфоксидом.

МАТЕРИАЛ И МЕТОДЫ. Экспериментальное исследование проведено на 20 глазах 10 кроликов породы шиншилла массой 2,5-3,0 кг, самцах. Кроликам под местной анестезией оксибупрокаином на обоих глазах с помощыо инсулинового шприца в стекловидное тело было введено 300 тысяч МТ (микробных тел) в 0,1 мл суточной культуры патогенных тест-штаммов Escherichia coli (150 тысяч МТ) (ATCC O55K5) и Staphylococcus aureus (150 тыс МТ) (АTCC 25923F-49). На вторые сутки у кроликов развивался эндофтальмит, после чего начинало проводиться лечение. Глаза кроликов были разделены на две группы. На 10 правых глазах кроликов - контрольная группа - проводилась стандартная противовоспалительная терапия, мидриаз. На левых глазах (основная группа) на фоне стандартной противовоспалительной терапии и мидриаза, ежедневно проводилась фотодинамическая терапия (ФДТ). Методика ФДТ заключалась в следующем: проводилась субконъюнктивальная инъекция 0,1 \% водного раствора метиленового синего (МС) и $10 \%$ диметисульфоксида, после чего через 30 мин, 1 час и 2 часа проводилось облучение диодным лазером с длиной волны 630-670 нм на протяжении трех минут [1]. Течение процесса контролировали посредством биомикроскопии, оценки степени воспалительной реакции по балльной системе критериев [5]. Посевы из конъюнктивальной полости, влаги передней камеры и содержимого витреаль- ной полости производились до инфицирования, на третьи сутки после инфицирования и каждые 7 дней в ходе лечения. Проводилось цветное фотографирование переднего отрезка глаза. Всем кроликам основной группы было выполнено УЗ-исследование на 15-е сутки после инфицирования. Срок наблюдения 20 дней.

РЕЗУЛЬТАТЫ. После проведенного лечения и наблюдения получены следующие результаты. В контрольной группе с эндофтальмитом (10 глаз) через сутки после вмешательства у всех кроликов появились блефароспазм, гиперемия и хемоз конъюнктивы, обильное отделяемое из конъюнктивальной полости, выраженный отек эпителия и стромы роговицы, опалесценция влаги передней камеры, отек радужки, желтый рефлекс с глазного дна. На вторые сутки, по данным бактериологического исследования, отмечался бурный рост Escherichia coli и Staphylococcus aureus, отмечались признаки выраженного воспалительного процесса. До конца наблюдения регресса воспаления не наблюдалось. Из-за помутнения оптических сред офтальмоскопия глазного дна была невозможна (Табл. 1). При посеве отделяемого конъюнктивальной полости, влаги передней камеры и содержимого витреальной полости наблюдался рост колоний Staphylococcus aureus и Escherichia coli.

В основной группе (10 глаз) через сутки после вмешательства у всех кроликов появились блефароспазм, гиперемия и хемоз конъюнктивы, обильное отделяемое из конъюнктивальной полости, выраженный отек эпителия и стромы роговицы, опалесценция влаги передней камеры, отек радужки, желтый рефлекс с глазного дна. На вторые сутки по данным бактериологического исследования, отмечался бурный рост Escherichia coli и Staphylococcus aureus, отмечались признаки выраженного воспалительного процесса. На 7 сутки после начала лечения отделяемого с конъюнктивальной полости не наблюдалось. На 13 сутки $(13 \pm 0,8)$ отмечалось уменьшение интенсивности гиперемии и отека конъюнктивы. С 8-х суток наблюдалось постепенное уменьшение отека роговицы, на 15-е сутки отека не было $(15 \pm 1,15)$. Длительность ирита составила $(13,75 \pm 0,5)$ дней. При офтальмоскопии отмечались помутнения в стекловидном теле. Рефлекс с глазного дна - белый (Табл. 2). Роста патогенной флоры нет. По данным УЗ-исследования - помутнение стекловидного тела, сетчатка прилежит, цилиарное тело не изменено, шварты между стекловидным телом и сетчаткой отсутствуют.

Таким образом, длительность течения эндофтальмита у кроликов, пролеченных ФДТ с метиленовым синим (основная группа), составляла $13,9 \pm 1,0$ дней. В контрольной группе воспалительный процесс наблюдался до конца срока наблюдения $(\mathrm{p}<0,05)$. При проведении ФДТ с МС у кроликов основной группы мы добились купирования воспаления и санации тканей глаза. 
Таблица 1

Оценка (в баллах) течения моделированного эндофтальмита у кроликов контрольной группы в динамике наблюдения

\begin{tabular}{|c|c|c|c|c|}
\hline Дни & $\begin{array}{c}\text { Конъюн- } \\
\text { ктива } \\
\text { (отек, } \\
\text { гиперемия, } \\
\text { выделения) }\end{array}$ & $\begin{array}{c}\text { Роговица } \\
\text { (отек) }\end{array}$ & $\begin{array}{c}\text { Радужка } \\
\text { (отек, } \\
\text { ирритация } \\
\text { сосудов, } \\
\text { синехии) }\end{array}$ & $\begin{array}{c}\text { Стекловид- } \\
\text { ное тело } \\
\text { (помутнение, } \\
\text { визуализация } \\
\text { глазного дна) }\end{array}$ \\
\hline 1 & $0,0 \pm 0,0$ & $0,0 \pm 0,0$ & $0,0 \pm 0,0$ & $0,0 \pm 0,0$ \\
\hline 2 & $2,17 \pm 0,41$ & $2,17 \pm 0,41$ & $2,0 \pm 0,0$ & $2,17 \pm 0,75$ \\
\hline 3 & $3,0 \pm 0,0$ & $3,0 \pm 0,0$ & $2,0 \pm 0,0$ & $2,83 \pm 0,41$ \\
\hline 4 & $3,0 \pm 0,0$ & $3,0 \pm 0,0$ & $2,3 \pm 0,52$ & $3,0 \pm 0,0$ \\
\hline 5 & $3,0 \pm 0,0$ & $3,0 \pm 0,0$ & $2,3 \pm 0,52$ & $3,0 \pm 0,0$ \\
\hline 6 & $3,0 \pm 0,0$ & $3,0 \pm 0,0$ & $2,7 \pm 0,52$ & $3,0 \pm 0,0$ \\
\hline 7 & $3,0 \pm 0,0$ & $3,0 \pm 0,0$ & $3,0 \pm 0,0$ & $3,0 \pm 0,0$ \\
\hline 8 & $3,0 \pm 0,0$ & $3,0 \pm 0,0$ & $3,0 \pm 0,0$ & $3,0 \pm 0,0$ \\
\hline 9 & $3,0 \pm 0,0$ & $3,0 \pm 0,0$ & $3,0 \pm 0,0$ & $3,0 \pm 0,0$ \\
\hline 10 & $3,0 \pm 0,0$ & $3,0 \pm 0,0$ & $3,0 \pm 0,0$ & $3,0 \pm 0,0$ \\
\hline 11 & $3,0 \pm 0,0$ & $3,0 \pm 0,0$ & $3,0 \pm 0,0$ & $3,0 \pm 0,0$ \\
\hline 12 & $3,0 \pm 0,0$ & $3,0 \pm 0,0$ & $3,0 \pm 0,0$ & $3,0 \pm 0,0$ \\
\hline 13 & $2,7 \pm 0,52$ & $3,0 \pm 0,0$ & $3,0 \pm 0,0$ & $3,0 \pm 0,0$ \\
\hline 14 & $2,7 \pm 0,52$ & $3,0 \pm 0,0$ & $2,83 \pm 0,41$ & $3,0 \pm 0,0$ \\
\hline 15 & $2,3 \pm 0,52$ & $2,5 \pm 0,55$ & $2,83 \pm 0,41$ & $3,0 \pm 0,0$ \\
\hline 16 & $2,3 \pm 0,52$ & $2,3 \pm 0,52$ & $2,83 \pm 0,41$ & $3,0 \pm 0,0$ \\
\hline 17 & $2,17 \pm 0,41$ & $2,3 \pm 0,52$ & $2,83 \pm 0,41$ & $3,0 \pm 0,0$ \\
\hline 18 & $2,17 \pm 0,41$ & $2,17 \pm 0,41$ & $2,83 \pm 0,41$ & $3,0 \pm 0,0$ \\
\hline 19 & $2,0 \pm 0,6$ & $2,17 \pm 0,41$ & $2,5 \pm 0,84$ & $3,0 \pm 0,0$ \\
\hline 20 & $2,0 \pm 0,6$ & $2,0 \pm 0,6$ & $2,5 \pm 0,84$ & $3,0 \pm 0,0$ \\
\hline
\end{tabular}

Таблица 2

Оценка (в баллах) течения моделированного эндофтальмита у кроликов основной группы в динамике наблюдения

\begin{tabular}{|c|c|c|c|c|}
\hline Дни & $\begin{array}{c}\text { Конъюн- } \\
\text { ктива } \\
\text { (отек, } \\
\text { гиперемия, } \\
\text { выделения) }\end{array}$ & $\begin{array}{c}\text { Роговица } \\
\text { (отек) }\end{array}$ & $\begin{array}{c}\text { Радуж- } \\
\text { ка (отек, } \\
\text { ирритация } \\
\text { сосудов, } \\
\text { синехии) }\end{array}$ & $\begin{array}{c}\text { Стекловид- } \\
\text { ное тело } \\
\text { (помутнение, } \\
\text { визуализация } \\
\text { глазного дна) }\end{array}$ \\
\hline 1 & $0,0 \pm 0,0$ & $0,0 \pm 0,0$ & $0,0 \pm 0,0$ & $0,0 \pm 0,0$ \\
\hline 2 & $2,0 \pm 0,0$ & $2,3 \pm 0,52$ & $2,0 \pm 0,0$ & $1,83 \pm 0,41$ \\
\hline 3 & $2,83 \pm 0,41$ & $3,0 \pm 0,0$ & $2,83 \pm 0,41$ & $2,67 \pm 0,52$ \\
\hline 4 & $3,0 \pm 0,0$ & $3,0 \pm 0,0$ & $2,3 \pm 0,52$ & $3,0 \pm 0,0$ \\
\hline 5 & $2,83 \pm 0,41$ & $3,0 \pm 0,0$ & $2,3 \pm 0,52$ & $3,0 \pm 0,0$ \\
\hline 6 & $2,5 \pm 0,55$ & $2,83 \pm 0,41$ & $2,3 \pm 0,52$ & $3,0 \pm 0,0$ \\
\hline 7 & $2,17 \pm 0,41$ & $2,5 \pm 0,55$ & $2,0 \pm 0,0$ & $3,0 \pm 0,0$ \\
\hline 8 & $2,0 \pm 0,0$ & $2,3 \pm 0,52$ & $1,5 \pm 0,55$ & $3,0 \pm 0,0$ \\
\hline 9 & $1,5 \pm 0,55$ & $2,17 \pm 0,41$ & $1,3 \pm 0,52$ & $3,0 \pm 0,0$ \\
\hline 10 & $1,17 \pm 0,41$ & $1,5 \pm 0.55$ & $1,0 \pm 0,0$ & $3,0 \pm 0,0$ \\
\hline 11 & $1,0 \pm 0,0$ & $1,3 \pm 0,52$ & $1,0 \pm 0,0$ & $3,0 \pm 0,0$ \\
\hline 12 & $0,67 \pm 0,52$ & $1,3 \pm 0,52$ & $1,0 \pm 0,0$ & $3,0 \pm 0,0$ \\
\hline 13 & $0,3 \pm 0,52$ & $1,0 \pm 0,0$ & $0,67 \pm 0,52$ & $3,0 \pm 0,0$ \\
\hline 14 & $0,0 \pm 0,0$ & $0,5 \pm 0,55$ & $0,0 \pm 0,0$ & $3,0 \pm 0,0$ \\
\hline 15 & $0,0 \pm 0,0$ & $0,3 \pm 0,52$ & $0,0 \pm 0,0$ & $3,0 \pm 0,0$ \\
\hline 16 & $0,0 \pm 0,0$ & $0,0 \pm 0,0$ & $0,0 \pm 0,0$ & $3,0 \pm 0,0$ \\
\hline 17 & $0,0 \pm 0,0$ & $0,0 \pm 0,0$ & $0,0 \pm 0,0$ & $3,0 \pm 0,0$ \\
\hline 18 & $0,0 \pm 0,0$ & $0,0 \pm 0,0$ & $0,0 \pm 0,0$ & $2,5 \pm 0,55$ \\
\hline 19 & $0,0 \pm 0,0$ & $0,0 \pm 0,0$ & $0,0 \pm 0,0$ & $2,3 \pm 0,52$ \\
\hline 20 & $0,0 \pm 0,0$ & $0,0 \pm 0,0$ & $0,0 \pm 0,0$ & $2,17 \pm 0,75$ \\
\hline
\end{tabular}

\section{ЗАКЛЮЧЕНИЕ}

Применение ФДТ с метиленовым синим в качестве фотосенсибилизатора и $10 \%$ диметисульфоксида как его проводника при экспериментальном эндофтальмите позволило сократить сроки лечения воспалительного процесса и добиться санации тканей глаза.

\section{ЛИТЕРАТУРА}

1. Пасечникова Н. В. Фотодинамическое воздействие метиленового синего на культуру Escherichia coli, с применением 10 \% диметилсульфоксида как проводника, при активации лазерным излучением с длиной волны 630 нм / Н. В. Пасечникова, А. В. Зборовская, Т. Б. Кустрин // Офтальмол.журн. - № 1. - 2010. C. 59-64.

2. Фиалков Ю. Я. Растворитель как средство управления химическим процессом/ Ю. Я. Фиалков // Л., Химия, 1990.

3. Basuk W. L. Complication of hexagonal keratotomy / W. L. Basuk, M. Zisman, G. O. Waring III et al // Am. J. Ophthalmol. - 1994. - Vol. 117(1). - P. 37-49.

4. Driebe W. T. Jr. Pseudophakic endophthalmitis: diagnosis and management / W. T. Driebe Jr., S. Mandelbaum, R. K. Forster et al // Ophthalmology. - 1986. - Vol. 93. P. 442-448.

5. Ermis SS. Treatment of Staphylococcus epidermidis endophthalmitis with intravitreal moxifloxacin in a rabbit model / SS Ermis, ZCetinkaya, H Kiyici, F Ozturk // Tohoku J Exp Med. - 2005 Mar. - Vol. 205(3). - P. 223-9.

6. Joondeth B. C. Purulent anterior segment endophthalmitis following paracentesis / B. C. Joondeth, H. C. Joondeth // Ophth. Surg. - 1986. - Vol. 17. - P. 91-93.

7. Mellish K. J. In vitro photodynamic activity of a series of methylene blue analogues/ K. J. Mellish, R. D. Cox, D. I. Vernon, J. Griffiths, S. B. Brown // Journal of Photochemestry and Photobiology. - 2002 Apr. - vol. 75. - Issue 4. - P. 392-7.

8. Salamon S. M. Endophthalmitis after strabismus surgery / S. M. Salamon, T. R. Frieberg, M. N. Luxenberg // Am. J. Ophthalmol. - 1982. - Vol. 93(1). - P. 39-41.

9. Schein O. D. Panophthalmitis after penetrating keratoplasty / O. D. Schein, J. W. Miller, M. D. Wagener // Arch. Ophthalmol. - 1989. - Vol. 107(1). - P. 21.

10. Usacheva M. N. Comparison of the methylene blue and toluidine blue photobactericidal efficacy against grampositive and gram-negative microorganisms/ M. N. Usacheva, M. C. Teichert, M. A. Biel // Lasers in Surgery and Medicine. - 2001. - vol. 29. - Issue 2. - P. 165-73.

Поступила 26.04.2011 Рецензент канд.мед.наук Н. Н. Уманец 
PHOTODYNAMIC THERAPY $0.1 \%$ METHYLENE BLUE WITH APPLICATION $10 \%$ A SOLUTION OF DIMETHYLSULFOXIDE IN THE TREATMENT OF ENDOPHTHALMITIS BACTERIAL ETIOLOGY

A. V. Zborovskaya

The use of methylene blue as a photosensitizer and $10 \%$ dimethyl sulfoxide as his guide, in the treatment of endophthalmitis in the experiment leads of reduces of the inflammatory process and sanation of eye tissues.

УДК 617.735+577.15:616.379-008.64-028.77+615.356-092.9

\title{
СОСТОЯНИЕ ЭНЗИМАТИЧЕСКОЙ АНТИОКСИДАНТНОЙ СИСТЕМЫ В СЕТЧАТКЕ ПРИ ЭКСПЕРИМЕНТАЛЬНОМ ДИАБЕТЕ И ПРИМЕНЕНИИ ВИТАМИНА В
}

\author{
К. П. Павлюченко, д. мед. н., проф., С. Ю. Могилевский, д. мед. Н., проф.,
}

А. Л. Чуйко, врач

Донецкий национальный медицинский университет им. М. Горького

\begin{abstract}
У статті наводяться результати вивчення стану ензиматичної антиоксидантної системи в сітківці при експериментальному стрептозотоциновому діабеті і вживанні різних форм вітаміну $_{6}$ (вітамерів - піридоксаміну, піридоксаля і піридоксину і коферментної форми - піридоксаль фосфату). Дослідження проводилися на білих шурах лінії Вістар. Було встановлено, що при експериментальному діабеті активність ферментів антиоксидантної системи (глутатіонпероксидази, каталази $i$ супероксиддісмутази) в сітківці понижена. Вжсивання різних форм вітаміну В запобігає пригніченню ферментів антиоксидантної системи. Найбільш виражена дія була у піридоксаль фосфату і піридоксаміну на глутатіонпероксидазу і супероксиддісмутазу.
\end{abstract}

Ключевые слова: сетчатка, экспериментальный диабет, энзиматическая антиоксидантная система, витамин $\mathrm{B}_{6}$.

Ключові слова: сітківка, експериментальний діабет, ензиматична антиоксидантна система, вітамін $\mathrm{B}_{6}$.

Введение. Сахарный диабет (СД) занимает третье место среди непосредственных причин смерти в мире после сердечно-сосудистых и онкологических заболеваний и ему принадлежит лидирующее положение по частоте осложнений, приводящих к ранней инвалидизации больных. В зависимости от типа и длительности течения сахарного диабета практически у всех больных развивается диабетическая ретинопатия, которая является одной из основных причин инвалидности по зрению у лиц трудоспособного возраста в экономически развитых странах $[1,2,3,9,10,14]$. Это требует разработки эффективных способов лечения диабетической ретинопатии, что возможно только на основе углубленного изучения патогенетических механизмов данного заболевания.

В ряде исследований появились убедительные доказательства роли свободно-радикальных процессов и, в частности, перекисного окисления липидов в механизме диабетических поражений сосудов и других тканевых структур. Свободные радикалы, дополнительно генерируемые при диабете в процессах аутоокисления глюкозы и гликозилирования белков, могут индуцировать перекисное окисление липидов не только в сосудистой системе, но и в мембранах клеточных и субклеточных структур тканей сетчатки [7, 14, 18, 22]. Необходимо также отметить, что источником образования свободнорадикальной формы кислорода - супероксидного радикала могут являться ксантиноксидазная и миелопероксидазная реакции, а также дыхательная цепь митохондрий. При этом доказано, что в сетчатке основное количество супероксидного радикала образуется при функционировании дыхательной цепи митохондрий, которая резко активируется в условиях гипергликемии [10, 17, 18, 23].

Наряду с этим установлено, что уровень биологических антиоксидантов (токоферола, глутатиона и др.) в организме диабетиков значительно снижен. А применение различных антиоксидантов животного и растительного происхождения замедляет развитие патологических изменений в сетчатке при сахарном диабете. Потенциальные возможности экзогенных антиоксидантов существенно ограничены вследствие их быстрого расходования для обезвреживания свободно-радикальных соединений и липопероксидов [22, 25]. Такая ситуация обусловливает необходимость изучения состояния

(ㄷ К. П. Павлюченко, С. Ю. Могилевский, А. Л. Чуйко, 2011 